\title{
Comparative Morphometry of the Sitophilus zeamais Motschulsky Populations (Coleoptera: Curculionidae) Infesting Yellow Maize in Four West African Countries
}

\author{
Adiouma Georges Robert Jacques Sarr, Cheikh Abdou Khadre Mbacké Dia, Tofféne Diome, \\ Pape Mbacké Sembene
}

\author{
Entomology and Acarology Laboratory, Animal Biology Department, Faculty of Sciences and Techniques, Cheikh Anta Diop \\ University of Dakar, Dakar, Senegal \\ Email: adioumageorges.sarr@ucad.edu.sn, cheikhabdoukhadrembacke.dia@ucad.edu.sn, Toffene.diome@ucad.edu.sn, \\ mbacke.sembene@ucad.edu.sn
}

How to cite this paper: Sarr, A.G.R.J., Dia, C.A.K.M., Diome, T. and Sembene, P.M. (2022) Comparative Morphometry of the Sitophilus zeamais Motschulsky Populations (Coleoptera: Curculionidae) Infesting Yellow Maize in Four West African Countries. Advances in Entomology, 10, 85-98. https://doi.org/10.4236/ae.2022.101007

Received: September 23, 2021

Accepted: January 3, 2022

Published: January 6, 2022

Copyright $\odot 2022$ by author(s) and Scientific Research Publishing Inc. This work is licensed under the Creative Commons Attribution International License (CC BY 4.0).

http://creativecommons.org/licenses/by/4.0/

\begin{abstract}
Sitophilus zeamais is a primary pest of stored maize, which can cause quality and quantity losses. Maize is cultivated in several West African countries where different agro-climatic and agro-ecological conditions exist. These conditions could influence the Sitophilus zeamais morphology. Thus, the purpose of this study is to identify the Sitophilus zeamais morphological groups in the four countries. This was carried out through the morphometric study of 30 male Sitophilus zeamais individuals taken from the yellow maize in each country, by measuring with a binocular magnifying glass, 16 variables of the different tagmas belonging to the insect. Subsequently, statistical analyses were firstly carried out with the raw measurements, such as the principal component analysis, in order to extract the contribution of the variables on each factorial axis and to visualise the correlations between the variables. Taking the case of the transformed measurements, in addition to the principal component analysis, a discriminant factorial analysis was carried out to find out the best factor for gathering individuals according to their morphology, a confusion matrix to summarise the individual's reclassification in order to deduce the good and bad classification rates, and an ascending hierarchical classification which consists of gathering the individuals according to their similarity and separating them according to their dissimilarity using the truncation method. Therefore, five morphological groups were identified. However, the existence of these morphological groups would not be linked to agro-ecological, climatic conditions and to the geographical remoteness between countries.
\end{abstract}




\section{Keywords}

Morphological Groups, Sitophilus zeamais, Maize

\section{Introduction}

Maize (Zea mays, Poaceae family) is a cereal cultivated alone or with several crops in various agro-ecological zones [1]. Its production enables people to survive the hunger periods in the rural areas. However, maize is infested in the field and during its storage by insect pests such as the Sitophilus zeamais (Motschulsky). This primary pest of stored maize can cause qualitative and quantitative losses [2] and thus encourage the colonisation of stocks by secondary pests and toxin-producing fungi such as the Aspergillus flavus [3]. These various types of damage reduce the quality of the grain and make it unfit for consumption [4]. However, estimating the losses caused by the $S$. zeamais is most of the time difficult because of its high variability, which can be explained by the agro-ecological conditions, the harvest period [2] [5] and even by the maize variety [2] [6]. Sitophilus zeamais is a cosmopolitan insect that can adapt itself to high temperatures and humidity [5]. It is widely distributed in tropical regions where it attacks standing crops [7]. In Africa, it is especially widespread on maize [5]. However, we noted that some African countries have different agro-climatic and agro-ecological conditions, while biodemographic profiles affect the biological strength of the insect [8]. Furthermore, the environmental factors, including agronomic practices (types of fertilisers, cultivation practices), influence the grain composition [9], the morphology and even the genetics of the insect population that infests the maize, as noted in the case of Caryedon serratus [10]. This context led us to ask whether the $S$. zeamais has the same morphology in the different West African agro-ecological areas where maize is cultivated in important quantities. In order to answer this scientific issue, the objective of this study will be to determine the existence of the $S$. zeamais morphometric groups in West Africa.

\section{Materials and Methods}

\subsection{Sampling}

The study areas were chosen according to the maize-producing countries, the infestation and taking into account the geographical location. Consequently, the sampling was carried out in four West African countries (Table 1). In our sampling strategy, maize was collected from the storage warehouses in those countries and kept in plastic bags. They were taken to the insectarium of the entomology and acarology laboratory of the Animal Biology Department of the Cheikh Anta Diop University of Dakar and transferred to jars for mass rearing. The $S$. zeamais adults that have emerged were collected and kept in $90 \%$ alcohol 
in test tubes, which were specific to each population. Each individual of a sample was coded, using the first letter of the genus name in uppercase followed by the first two letters of the country of origin (the first letter in uppercase and the second in lowercase), the colour of the maize type and finally a serial number. For example, the SSeJ1 code represents a Sitophilus zeamais individual from Senegal, on yellow (Jaune) maize, with order number 1 (Table 2).

\subsection{Morphometric Study}

The biological material used for the morphometry was composed of male Sitophilus zeamais taken from the maize mass rearing. The choice of males for the morphometric study was explained by the fact that females can change their morphologies and as a result bias the measurements. The male identification compared to the female was based on criteria established by [5] study dealing with the insects found in foodstuffs. The male's rostrum was shorter and thicker, but less smooth than the female's rostrum; the ventral face of the abdomen was concave to the apex of the male, approximately flat in the female. The insect was removed from the alcoholic solution using pliers, placed in distilled water and then transferred on paper towel to be dried (the paper sucked up the water in which the insect was soaked). It was then placed on a graph paper in a binocular magnifying glass to proceed to the measurements. The insect was first dissected using pliers by separating its three tagmas: head, thorax and abdomen. Each tagma was then separated from its different articles. A total of sixteen (16) variables were measured with a reasonable degree of accuracy $( \pm 1 \mathrm{~mm})$ (Table 3$)$ (Figure 1).

Table 1. Table of sampled countries.

\begin{tabular}{|c|c|c|}
\hline \multirow{2}{*}{ Countries } & \multicolumn{2}{|c|}{ Geographical coordinates } \\
\hline & Latitude & Longitude \\
\hline Senegal & $12^{\circ} 00^{\prime}-16^{\circ} 30^{\prime}$ North & $11^{\circ} 30^{\prime}-17^{\circ} 30^{\prime}$ West \\
\hline Guinea Conakry & $07^{\circ} 05^{\prime}-12^{\circ} 51^{\prime}$ North & $07^{\circ} 30^{\prime}-15^{\circ} 10^{\prime}$ West \\
\hline Mali & $10^{\circ} 00^{\prime}-25^{\circ} 00^{\prime}$ North & $4^{\circ} 00^{\prime}-12^{\circ} 00^{\prime}$ West \\
\hline Ghana & $04^{\circ} 44^{\prime}-11^{\circ} 11^{\prime}$ North & $01^{\circ} 11^{\prime}-3^{\circ} 11^{\prime}$ West \\
\hline
\end{tabular}

Table 2. Table of sampling summary.

\begin{tabular}{cccc}
\hline Countries & Maize types & Number of samples & Sample Code \\
\hline Senegal & Yellow & 30 & SSeY \\
Guinea Conakry & Yellow & 30 & SGuY \\
Mali & Yellow & 30 & SMaY \\
Ghana & Yellow & 30 & SGaY \\
\hline
\end{tabular}


Table 3. Measured variables.

\begin{tabular}{|c|c|c|}
\hline \multicolumn{3}{|c|}{ Measured variables } \\
\hline Head & Thorax & Abdomen \\
\hline \multirow{10}{*}{$\begin{array}{l}\text { Length of the rostrum (Lr) } \\
\text { The width of the rostrum } \\
\text { (Lar) } \\
\text { Length of the antenna (Lan) }\end{array}$} & Length of the pronotum (Lop) & \multirow{10}{*}{$\begin{array}{l}\text { Width of the pygidium (lpy) } \\
\text { Thickness of the pygidium } \\
\text { (Epy) } \\
\text { Length of the first sternum } \\
\text { (Los1) }\end{array}$} \\
\hline & Width of the pronotum (Lap) & \\
\hline & Length of the wing (Loa) & \\
\hline & Width of the of the wing (Laa) & \\
\hline & Length of the elytra (Loe) & \\
\hline & Width of the elytra (Lae) & \\
\hline & Length of the tibia 3 (LT3) & \\
\hline & Length of the femur 3 (Lf3) & \\
\hline & Length of the coxa 3 (Lc3) & \\
\hline & Length of the tarse 3 (Lt3) & \\
\hline
\end{tabular}
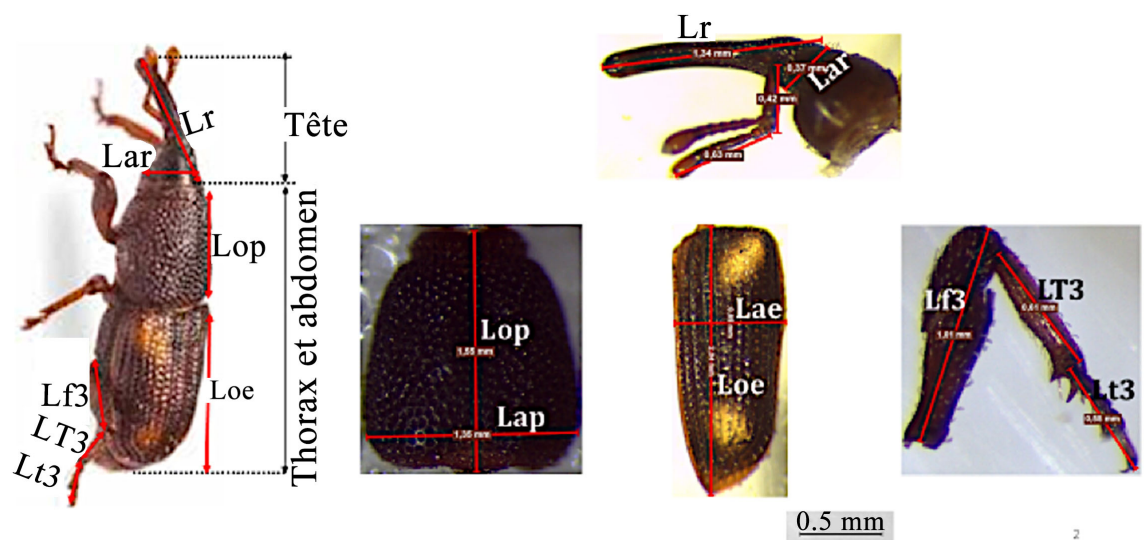

Figure 1. View of the measured variables.

\subsection{Statistical Analysis}

\subsubsection{Raw Measurements}

After choosing the number of axes to be retained, according to the elbow criterion (which allows to obtain the best factorial design), a Principal Component Analysis (PCA) of the populations with the variable's raw measurements using the R software version 3.2.3 of R Core Team (2014). The PCA aims to highlight the contribution of the variables on each factorial axis, to visualize the correlations between the variables.

\subsubsection{Transformed Measurements}

\section{Size effect and data transformation}

The size effect is explained by a correlation circle that gathers all the variables in a single plan for a given axis. This is an unwanted effect, which metric studies are trying to escape [11]. The principle is therefore to eliminate this effect and to bring back all individuals to the same size, so that only shape differences can be observed on the PCA. The removal of the size effect in this study was carried out 
according to the approach proposed by [11] [12] [13] [14] [15].

- Data log-transformation: our initial data table was made up of variables named X1, X2, .., Xp, we later created a new data table made up of the variables $\log (\mathrm{X} 1), \log (\mathrm{X} 2), \ldots, \log (\mathrm{Xp})$;

- For each individual, we computed the average of all the log-transformed variables. We consider that this average score gives a good idea regarding the "size" for this individual;

- Finally, for each individual, we subtracted from each of these raw measurements the average size obtained with the log-transformed data.

Therefore, the size effect was eliminated and only the difference of shape will be observed on the PCA. The elimination of the factor (Size) leads to a decrease in the total discrimination. This transformation was carried out using Excel 2010 version.

\section{Discriminant factor analysis}

A discriminant factor analysis (DFA) of the populations with the variables transformed data was carried out using the software $\mathrm{R}$ version 3.2.3. It was performed with the variables whose contribution value is the same or bigger than $(1 / \mathrm{P}) \times 100$. Its purpose is to find out the best factor in order to gather individuals according to their morphology.

Determination of variables discriminating the populations

In order to determine the variables that significantly differentiate the populations morphology, a Shapiro-Wilk normality data test was firstly performed on each transformed log-variable. When the p-value of the test is less than 0.05 (the case of all transformed log-variables in this study), the data of the corresponding transformed-log do not follow the normal law and the Kruskal-Wallis test (non-parametric) was performed for a multiple average rank's comparison of the corresponding variable related to the populations. The Wilcoxon test (non-parametric) coupled with the Bonferroni adjustment was performed to test the average variations significance rank regarding the transformed log-variables per pair of populations.

\section{Confusion matrix for cross-validation results}

The confusion matrix summarizes the reclassifications of the individuals to deduce the good and bad classifications rates. This will allow to determine the "correct percentage (\%)", which is the ratio between the number of well-ranked individuals and the total number of individuals. The cross-validation is applied on the log-transformed data using the XLSTAT program version 2016.03.30882 (Addinsoft, 2016).

\section{Ascending hierarchical classification (AHC)}

The ascending hierarchical classification aims to identify a posteriori classes that are not obvious a priori. It consists in gathering individuals, using the truncation method, with respect to their similarity and separating them according to their dissimilarity. Its purpose is to identify morphologically homogeneous groups from the variables point of view. It was performed with XLSTAT program version 2016.03.30882 (Addinsoft, 2016). 


\section{Results}

\subsection{Raw Measurements}

\subsubsection{Choice of the Number of Axes to Be Retained}

In order to have the number of axes, we accordingly used the elbow criterion. The purpose of this method is to obtain the maximum kept inertia with the minimum number of factors. In our research, two axes were selected, because the cut-off (the elbow) is found at $\mathrm{K}=2$ (Figure 2).

\subsubsection{Principal Component Analysis}

The principal component analysis shows that the first two factorial axes (dimensions) better explain the morphometric variability with $43.8 \%$ percentage of inertia. Variables such as Lae $(\mathrm{F} 1=13.2)$, Loe $(\mathrm{F} 1=11.24)$, LT3 $(\mathrm{F} 1=10.5)$, Loa $(\mathrm{F} 1=$ 9.77), $\operatorname{Lap}(\mathrm{F} 1=8.76), \operatorname{Lr}(\mathrm{F} 1=7.39), \operatorname{Los} 1(\mathrm{~F} 1=7.53)$ and $\operatorname{Lan}(\mathrm{F} 1=7.25)$ largely participate in the construction of the first factorial axis with $30.86 \%$ of the power of inertia (Figure 3). The others such as Lar $(\mathrm{F} 1=6.23)$, Epy (F1 $=4.64)$, Lop (F1 = 3.81), Laa $(\mathrm{F} 1=3.64), \mathrm{Lpy}(\mathrm{F} 1=2.79), \mathrm{Lf} 3(\mathrm{~F} 1=2.63), \mathrm{Lc} 3(\mathrm{~F} 1=0.56)$ and Lt3 $(\mathrm{F} 1=0.10)$ lowly participate to the construction of this factorial axis. The factorial axis two (Dim 2) with a low percentage of inertia (12.91\%) is constructed with the variables Lpy (F2 = 17.5), Lar (F2 = 17.4), Lop (F2 = 12.2), Epy (F2 = 12.1), Lr (F2 $=8.16)$, Lap $(\mathrm{F} 2=7.64)$, Los1 $(\mathrm{F} 2=6.92)$ and $\mathrm{Laa}(\mathrm{F} 2=6.7)$. Other variables such as Lan $(\mathrm{F} 2=5.76)$, Lt3 $(\mathrm{F} 2=2)$, Loa $(\mathrm{F} 2=1.47)$, Lae $(\mathrm{F} 2=0.66)$, Lf3 $(\mathrm{F} 2=0.5)$, Lc3 $(\mathrm{F} 2=0.37)$, Loe $(\mathrm{F} 2=0.33)$, LT3 $(\mathrm{F} 2=0.32)$ lowly participate to the construction of this axis. On the first factorial axis all variables except Lc3 are positively correlated because they have the same sign. With respect to the above, it is clearly noted that the size effect affected our PCA (Figure 3).

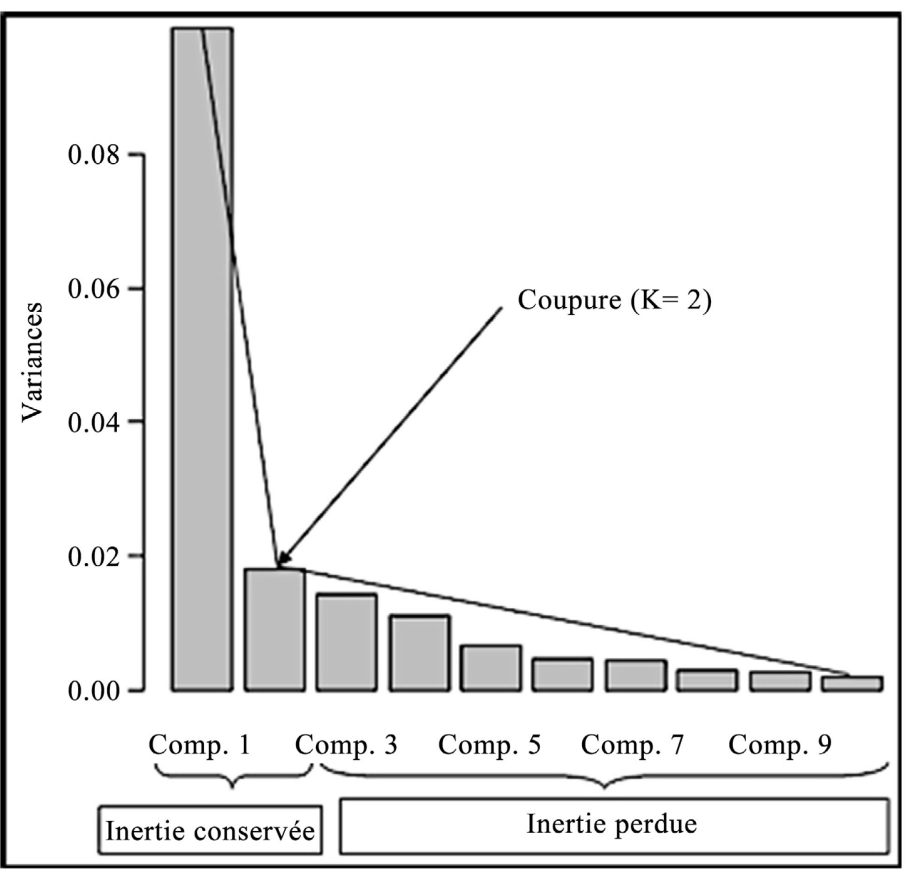

Figure 2. Choice of the number of factors. 


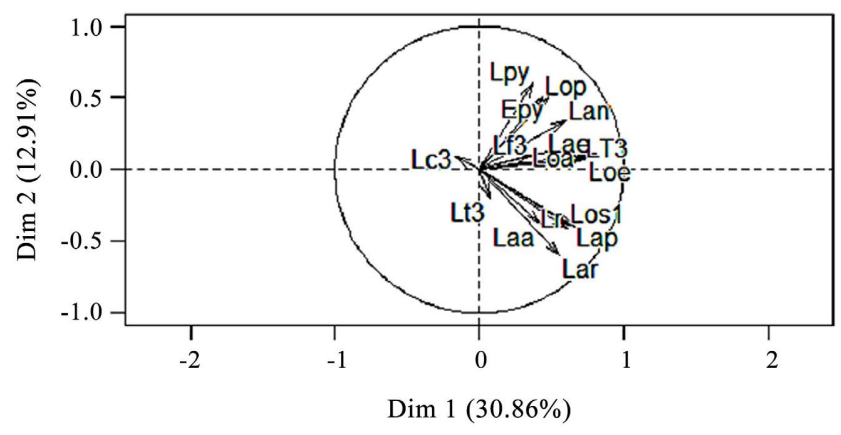

Figure 3. Correlation of variables according to their participation to the construction of the 2 dimensions (Dim. 1 and Dim. 2) with the raw data belonging to the populations.

\subsection{Transformed Measurements}

\subsubsection{Choice of the Number of Axes to Be Retained after Data Transformation}

After the data transformation, the chosen number of axes obtained using the elbow criterion is the same as before the transformation (Figure 4).

\subsubsection{Principal Component Analysis of Transformed Variables}

The Principal Component Analysis (PCA) revealed after data transformation that the first factorial axis lost $8.08 \%$ of its percentage of inertia. On the other hand, the percentage of inertia of the second factorial axis increased up to $3.46 \%$. As a result, the percentage of inertia of the first two axis was equivalent to $39.17 \%$. The best representation quality is always obtained with these first two axis. On the first factorial axis, with a percentage of inertia equivalent to $22.80 \%$, the contribution of some variables is lower than the values obtained before transformation. This is noted with the length of the wing $(\mathrm{F} 1=7.92)$, the width of the pronotum $(\mathrm{F} 1=5.31)$, the length of the rostrum $(\mathrm{F} 1=4.49)$, the length of the antenna $(\mathrm{F} 1=2.76)$, the width of the rostrum $(\mathrm{F} 1=1.44)$, the thickness of the pygidium $(\mathrm{F} 1=0.38)$, the width of the wing $(\mathrm{F} 1=0.37)$, the length of the femur $3(\mathrm{~F} 1=0.30)$, the length of the pygidium $(\mathrm{F} 1=0.25)$ and the length of the pronotum $(\mathrm{F} 1=0.01)$. On the other hand, the contribution of some variables increased. This is noted with the length of the elytra $(\mathrm{F} 1=18.7)$, the length of the tibia $3(F 1=17.2)$, the width of the elytra $(F 1=17.1)$, the length of the coxa 3 $(\mathrm{F} 1=15.5)$ and the length of the tarsus $3(\mathrm{~F} 1=5.90)$. Following the second factorial axis (16.37\% percentage of inertia), the contribution of certain variables decreased compared to the values obtained before transformation. These variables are the length of the pygidium $(\mathrm{F} 2=15.8)$, the length of the pronotum (F2 $=7.66)$, the width of the wing $(\mathrm{F} 2=6.55)$, the length of the antenna $(\mathrm{F} 2=4.06)$, the length of the coxa $3(\mathrm{~F} 2=0.097)$ and the length of the femur $3(\mathrm{~F} 2=0.006)$. On the other hand, the contribution of some variables increased. This is the case of the width of the rostrum ( $\mathrm{F} 2=20.08)$, the thickness of the pygidium $(\mathrm{F} 2=$ $12.8)$, the width of the pronotum $(\mathrm{F} 2=8.99)$, the length of the rostrum $(\mathrm{F} 2=$ 8.56), the length of the first sternum $(\mathrm{F} 2=7.76)$, the length of the tarsus $3(\mathrm{~F} 2=$ $2.07)$, the length of the elytra $(\mathrm{F} 2=1.26)$ and the length of the tibia $3(\mathrm{~F} 2=1.29)$. 
The removal of the size effect was materialised by the dispersion of the variables on both sides of the two axes (Figure 5).

\subsubsection{Discrimination after Transformation}

The best representation quality is always obtained with the diagram composed of the first two axes (Dim 1 and Dim 2) with $45.76 \%$ of inertia. Following the first axis for a percentage of inertia equivalent to $26.37 \%$, two morphometric groups were identified with more or less important areas of introgression. On the one hand, they are individuals from the population of Guinea Conakry, and on the other hand individuals from Senegal, Mali and Ghana. According to the second factorial axis, for a percentage of inertia equivalent to $19.39 \%$, individuals from the population of Ghana are different from individuals belonging to the population of Senegal and Mali, with a zone of introgression between them (Figure 6).

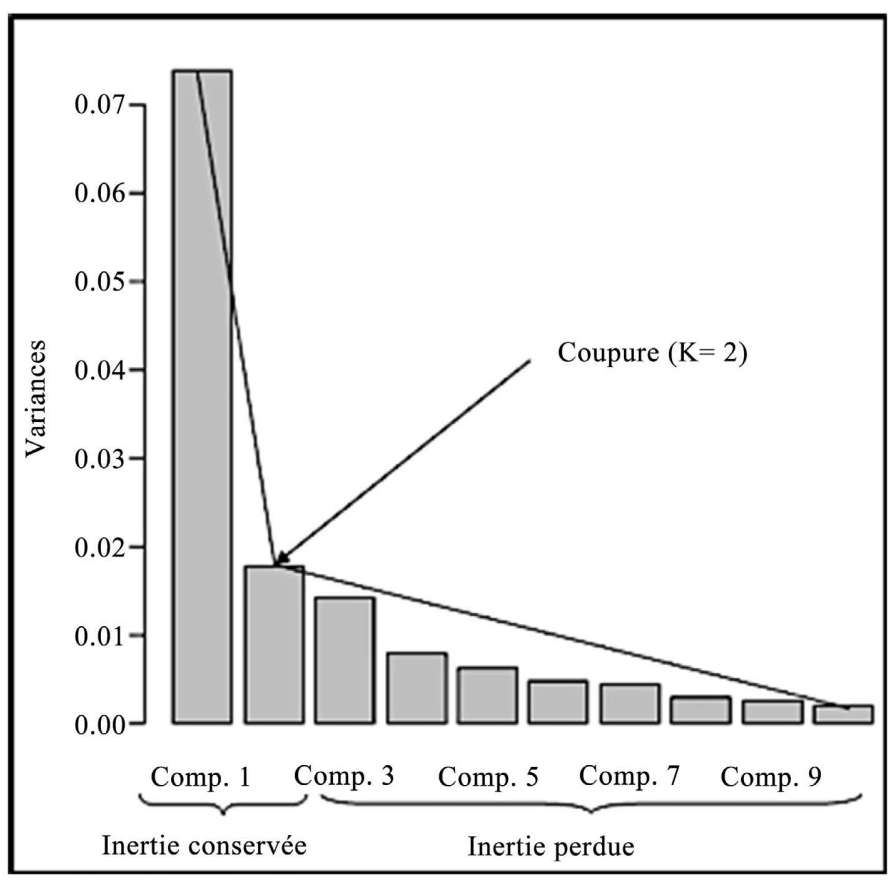

Figure 4. Choice of the number of factors after data transformation.

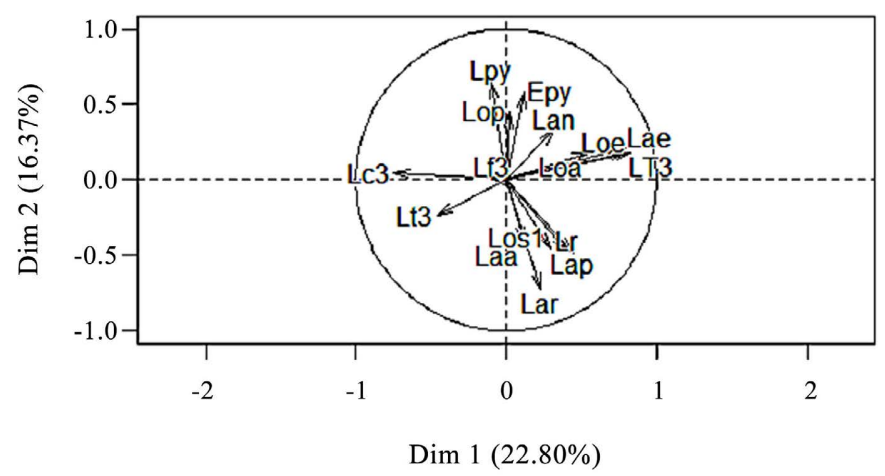

Figure 5. Correlation of variables according to their participation to the construction of the 2 dimensions (Dim. 1 and Dim. 2) with the transformed data of the populations. 


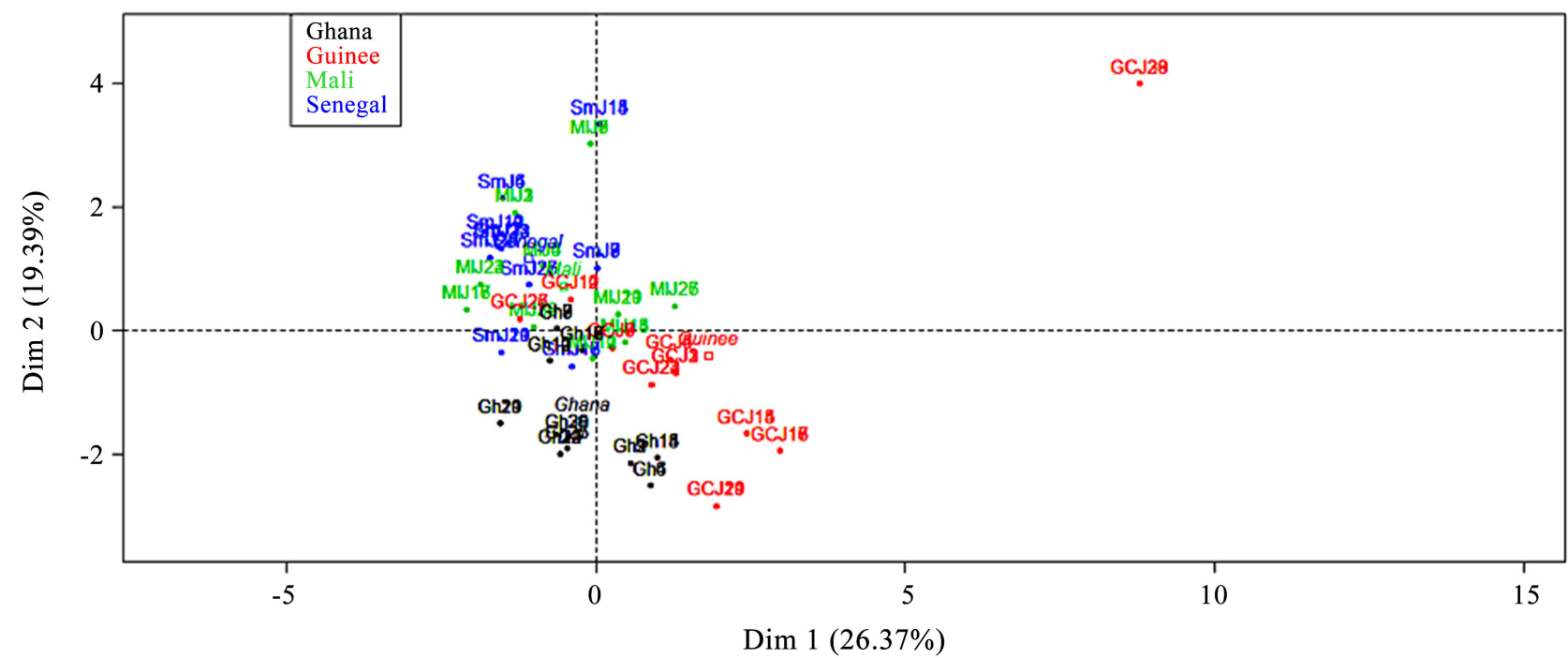

Figure 6. View of the principal plan representing the Discriminant Factor Analysis of the Sitophilus zeamais populations after transformation of variables.

\subsubsection{Variables Allowing Discrimination after Transformation}

According to the first axis (Dim), the morphological difference between the individuals belonging to the population of Senegal compared to those belonging to the population of Guinea Conakry were significantly explained by the length of the rostrum, the width of the rostrum (Lr), the length of the pronotum (Lop), the width of the pronotum (Lap), the length of the wing (Loa), the length of the elytra (Loe), the width of the elytra (Lae), the length of the tibia 3 (LT3), the length of the coxa 3 (Lc3), the length of the pygidium (Lpy) and the thickness of the pygidium (Epy). The latter significantly explain the morphological differences noted between the populations of Guinea Conakry and Mali, excepted the thickness of the pygidium (Epy). Between the population of Guinea Conakry and Ghana, variables such as the length of the rostrum (Lr), the width of the rostrum (Lar), the length of the pronotum (Lop), the width of the pronotum (Lap), the width of the wing (Laa), the length of the pygidium (Lpy) and the thickness of the pygidium (Epy) significantly explain the morphological differences between these two populations. According to the second factorial axis (Dim 2), the morphological differences between the population of Ghana and the population of Mali were explained by the length of the rostrum (Lr), the width of the rostrum (Lar), the length of the pronotum (Lop), the length of the wing (Loa) and the length of the pygidium (Lpy). Between the populations of Ghana and Senegal, the length of the rostrum (Lr), the width of the rostrum (Lar), the length of the pronotum (Lop), the width of the pronotum (Lap), the width of the wing (Laa), the length of the pygidium (Lpy) and the thickness of the pigidium (Epy) significantly explain the morphological differences between those populations (Table 4).

The transformed log-variables averages noted with different letters are significantly different and those noted with the same letters are not significantly different. 
Table 4. Significance test of transformed log-variables averages of the populations.

\begin{tabular}{ccccc}
\hline Populations variables & Ghana & Guinea Conakry & Mali & Senegal \\
\hline Lr & $1.58 \pm 0.07^{\mathrm{b}}$ & $1.58 \pm 0.06^{\mathrm{b}}$ & $1.52 \pm 0.06^{\mathrm{a}}$ & $1.50 \pm 0.06^{\mathrm{a}}$ \\
Lar & $0.58 \pm 0.04^{\mathrm{b}}$ & $0.58 \pm 0.05^{\mathrm{b}}$ & $0.53 \pm 0.05^{\mathrm{a}}$ & $0.51 \pm 0.05^{\mathrm{a}}$ \\
Lan & $1.01 \pm 0.04^{\mathrm{a}}$ & $1.06 \pm 0.06^{\mathrm{b}}$ & $1.06 \pm 0.04^{\mathrm{b}}$ & $1.07 \pm 0.06^{\mathrm{b}}$ \\
Lop & $1.27 \pm 0.05^{\mathrm{a}}$ & $1.30 \pm 0.04^{\mathrm{a}}$ & $1.42 \pm 0.09^{\mathrm{c}}$ & $1.36 \pm 0.05^{\mathrm{b}}$ \\
Lap & $1.10 \pm 0.04^{\mathrm{bc}}$ & $1.13 \pm 0.08^{\mathrm{c}}$ & $1.10 \pm 0.04^{\mathrm{b}}$ & $1.05 \pm 0.04^{\mathrm{a}}$ \\
Loa & $3.22 \pm 0.20^{\mathrm{a}}$ & $3.59 \pm 0.21^{\mathrm{c}}$ & $3.42 \pm 0.19^{\mathrm{b}}$ & $3.27 \pm 0.09^{\mathrm{a}}$ \\
Laa & $1.21 \pm 0.05^{\mathrm{c}}$ & $1.13 \pm 0.10^{\mathrm{b}}$ & $1.18 \pm 0.08^{\mathrm{bc}}$ & $1.05 \pm 0.15^{\mathrm{a}}$ \\
Loe & $1.81 \pm 0.04^{\mathrm{a}}$ & $2.06 \pm 0.57^{\mathrm{b}}$ & $1.84 \pm 0.06^{\mathrm{a}}$ & $1.82 \pm 0.08^{\mathrm{a}}$ \\
Lae & $0.83 \pm 0.02^{\mathrm{a}}$ & $0.90 \pm 0.10^{\mathrm{b}}$ & $0.85 \pm 0.05^{\mathrm{a}}$ & $0.86 \pm 0.03^{\mathrm{a}}$ \\
LT3 & $0.75 \pm 0.05^{\mathrm{a}}$ & $0.87 \pm 0.33^{\mathrm{b}}$ & $0.75 \pm 0.04^{\mathrm{a}}$ & $0.73 \pm 0.06^{\mathrm{a}}$ \\
Lf3 & $0.95 \pm 0.04^{\mathrm{a}}$ & $0.97 \pm 0.06^{\mathrm{a}}$ & $0.98 \pm 0.05^{\mathrm{a}}$ & $0.94 \pm 0.08^{\mathrm{a}}$ \\
Lc3 & $0.34 \pm 0.01^{\mathrm{b}}$ & $0.30 \pm 0.04^{\mathrm{a}}$ & $0.33 \pm 0.03^{\mathrm{b}}$ & $0.33 \pm 0.03^{\mathrm{b}}$ \\
Lt3 & $0.59 \pm 0.05^{\mathrm{a}}$ & $0.57 \pm 0.07^{\mathrm{a}}$ & $0.57 \pm 0.04^{\mathrm{a}}$ & $0.56 \pm 0.05^{\mathrm{a}}$ \\
Lpy & $0.51 \pm 0.03^{\mathrm{a}}$ & $0.52 \pm 0.05^{\mathrm{a}}$ & $0.62 \pm 0.05^{\mathrm{b}}$ & $0.59 \pm 0.05^{\mathrm{b}}$ \\
Epy & $0.81 \pm 0.04^{\mathrm{a}}$ & $0.81 \pm 0.03^{\mathrm{a}}$ & $0.82 \pm 0.04^{\mathrm{ab}}$ & $0.85 \pm 0.06^{\mathrm{b}}$ \\
Los1 & $1.08 \pm 0.04^{\mathrm{a}}$ & $1.07 \pm 0.05^{\mathrm{a}}$ & $1.06 \pm 0.04^{\mathrm{a}}$ & $1.06 \pm 0.03^{\mathrm{a}}$ \\
\hline & & & & \\
\hline
\end{tabular}

\subsubsection{Confusion Matrix for the Cross-Validation of Populations}

The confusion matrix summarizes the reclassifications of individuals to deduce the good and bad classifications rates. This will allow the determination of the "correct \%", which is the ratio of the number of well-ranked individuals to the total number of individuals. Thus, the cross-validation of the individuals in the populations reveals that $92.5 \%$ of the individuals are well classified in their original population. Indeed, the individuals from the populations of Ghana and Guinea are the most homogeneous with $100 \%$ of well-ranked individuals. Individuals belonging to the populations of Mali and Senegal are less homogenous compared to the others, respectively with $80 \%$ and $90 \%$ of well-ranked individuals (Table 5).

\subsubsection{Ascending Hierarchical Classification of Individuals}

The dotted line represents the truncation and shows five morphological groups: Gr1 (2.5\% among individuals of the total population), Gr2 (2.5\%), Gr3 (20\%), Gr4 (52.5\%) and Gr5 (27\%) (Figure 7). Groups_1 and _2 are made up respectively of individuals from Guinea Conakry (100\%) and Senegal (100\%). Individuals belonging to Guinea Conakry (12.5\%) and Ghana $(87.5 \%)$ form the group_3. As for group_4, it is made up of individuals from Mali (38\%), Senegal (23.8\%), Guinea Conakry (23.8\%) and Ghana (14.4\%). The last group (group_5) consists of individuals from Senegal (44.5\%), Guinea Conakry (33.3\%) and Mali (22.2\%). According to the ascending hierarchical classification by similarity, individuals from Guinea Conakry are morphologically the most heterogeneous, with $10 \%$ of their individuals in group_1, 10\% in group_3, 50\% in group_4 and $30 \%$ in group_5. This is followed by individuals from Senegal, $10 \%$ of them are 
classified in group_2, 50\% in group_4 and 40\% in group_5. On the other hand, individuals from Ghana and Mali are the less heterogeneous based on their morphologies. Individuals from Ghana are 70\% in group_3 and 30\% in group_4. Those from Mali are found in group_4 (80\%) and in group_5 (20\%) (Table 6).

Table 5. The confusion matrix for the cross-validation of populations.

\begin{tabular}{ccccccc}
\hline From $\backslash$ To & Ghana & Guinea & Mali & Senegal & Total & $\%$ correct \\
\hline Ghana & 30 & 0 & 0 & 0 & 30 & $100.00 \%$ \\
Guinea & 0 & 30 & 0 & 0 & 30 & $100.00 \%$ \\
Mali & 0 & 0 & 24 & 6 & 30 & $80.00 \%$ \\
Senegal & 0 & 0 & 3 & 27 & 30 & $90.00 \%$ \\
Total & 30 & 30 & 27 & 33 & 120 & $92.50 \%$ \\
\hline
\end{tabular}

Table 6. Composition of morphometric groups and distribution of individuals in each group.

\begin{tabular}{ccccc}
\hline \multicolumn{5}{c}{ Composition of morphometric groups } \\
\hline Countries groups & Guinea Conakry & Senegal & Ghana & Mali \\
\hline Gr_1 (2.5\%) & $100 \%$ & ---- & ---- & ---- \\
Gr_2(2.5\%) & ---- & $100 \%$ & ---- & ---- \\
Gr_3 (20\%) & $12.5 \%$ & ---- & $87.5 \%$ & ---- \\
Gr_4 (52.5\%) & $23.8 \%$ & $23.8 \%$ & $14.4 \%$ & $38 \%$ \\
Gr_5 (27\%) & $33.3 \%$ & $44.5 \%$ & ---- & $22.2 \%$
\end{tabular}

Distribution of individuals in the groups

\begin{tabular}{cccccc}
\hline Groups Countries & $\mathrm{Gr} \_1$ & $\mathrm{Gr} \_2$ & $\mathrm{Gr} \_3$ & $\mathrm{Gr}_{-} 4$ & $\mathrm{Gr} \_5$ \\
\hline Guinée Conakry & $10 \%$ & ---- & $10 \%$ & $50 \%$ & $30 \%$ \\
Senegal & ---- & $10 \%$ & ---- & $50 \%$ & $40 \%$ \\
Ghana & ---- & ---- & $70 \%$ & $30 \%$ & ---- \\
Mali & ---- & ---- & ---- & $80 \%$ & $20 \%$ \\
\hline
\end{tabular}

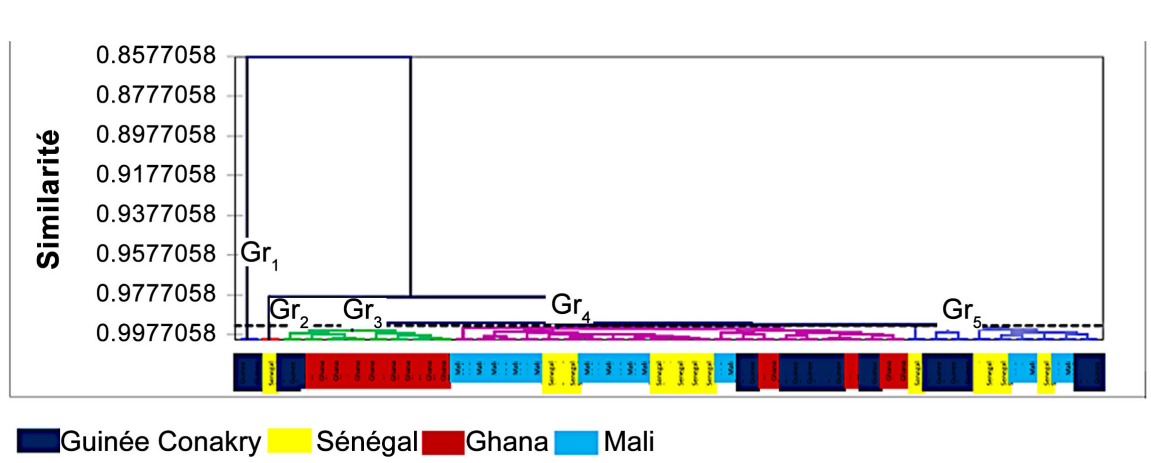

Figure 7. Ascending hierarchichal classification of the individuals. $\mathrm{Gr}_{1}$ (groupe_1), $\mathrm{Gr}_{2}$ (groupe_2), $\mathrm{Gr}_{3}$ (groupe_3), $\mathrm{Gr}_{4}$ (groupe_4), $\mathrm{Gr}_{5}$ (groupe_5). 


\section{Discussion}

According to the elbow criterion, two factorial axes were selected for raw measurements and transformed data. These two factorial axes reveal a greater variability in the morphometric properties for the raw measurements compared to the transformed measurements. This difference noted in the percentage of inertia reflects the elimination of the size effect between them. After the elimination of the size effect, individuals from Senegal, Mali and Ghana reveal similarities between them and dissimilarity between the individuals from Guinea Conakry. However, similarities are noted between individuals from geographically remote countries with different agro-ecological conditions. Geographical remoteness between countries does not seem to be a determining factor in the similarities, as noted in the morphometric identification study of the Sudano-Sahelian population of Caryedon serratus [16]. Therefore, the similarities and dissimilarities would neither be linked to agro-ecological and climatic conditions, nor to the geographical distance between the countries. The confusion matrix analysis regarding the results of the cross-validation of yellow maize populations showed that individuals from the populations of Ghana and Guinea Conakry are the most homogeneous and those from Mali and Senegal are the most heterogeneous. The homogeneity of individuals in Ghana would be explained by the fact that Ghana is a maize exporting country [17]. There are few or no individuals of S. zeamais from other countries. As for the population of Guinea Conakry, although they are maize importing country [17], their homogeneity could be explained by the increase of local maize production marked by the predominance of family farming [18]. Individuals of $S$. zeamais are originated from this local maize. The heterogeneity of the individuals belonging to Mali and Senegal would come from the importation of one part of the maize. These two countries respectively import $17 \%$ and $12 \%$ of their maize [19]. An ascending hierarchical classification study of individuals revealed a similarity between certain populations. Five morphometric groups were identified, with the individuals of Guinea having the most varied morphology. However, the similarities noted between certain individuals confirm only the morphological similarities that were identified between certain populations in the discriminant factor analysis of the populations. This is the case of the individuals from Senegal, Ghana and Mali, which are found in morphometric group 4, but morphometric groups 1 and 2 are respectively specific to the populations of Guinea Conakry and Senegal. The existence of these specific morphometric groups could be explained either by the agro-ecological conditions or by the storage conditions in those countries, knowing that according to [20] in Guinea Conakry, the appropriate means of storage are not sufficient. The ears are most of the time poorly stored, and are subject to any phytosanitary treatment. The warehouses are poorly aerated and are hotbeds for insect's proliferation. Therefore, in this country, a group of insects would be permanently present in the cultivation areas. Consequently, such storage conditions would be favourable for a closed reproduction system. 
Taking the case of Senegal, infestation on stored maize begins during the drying of the ears in the field [21]. In addition, the storage means are mostly rudimentary and aeration system is not respected [21], promoting the multiplication of insects. Moreover, the same warehouses are used upon each harvest operation. The new individuals are generated by the individuals that firstly infested the stocks, which would make the reproduction system closed to other individuals. This reproduction system could be at the origin of this morphometric group that is specific to Senegal.

\section{Conclusion}

The determination of $S$. zeamais morphometric groups in West Africa is of the utmost importance. It enables to find out whether the morphology of this insect depends on its geographical origin and to develop traceability of this insect pest for a better sustainable fighting strategy. Discriminant factorial analysis revealed the existence of morphometric groups that would not be linked to agro-ecological and climatic conditions and to the geographical remoteness of countries. As a matter of fact, a genetic study is needed to find out if the morphometric differences detected are observable at the molecular level using mitochondrial genes.

\section{Conflicts of Interest}

The authors declare no conflicts of interest regarding the publication of this paper.

\section{References}

[1] Escalante, M., Hoopen, T. and Maïga, A. (2012) Maize Production and Transformation [Production et transformation du maïs]. PRO-AGRO Collection, $32 \mathrm{p}$.

[2] Ngamo, L.T.S., Boura, A.F., Ngassoum, M.B., Mapongmestsem, P.M. and Hance, H. (2007) Damage Assessment of 25 Local Strains of Sitophilus zeamais Motsch. (Coleoptera: Curculionidae) on White Maize CMS 8501 [Evaluation des dégâts de 25 souches locales de Sitophilus zeamais Motsch. (Coleoptera: Curculionidae) sur le maïs blanc CMS 85 01]. Cameroon Journal of Experimental Biology, 3, 11-19.

[3] Gueye, M.T., Seck, D., Watheley, J.P. and Lognay G. (2011) Lutte contre les ravageurs des stocks de céréales et de légumineuses au Sénégal et en Afrique occidentale: Synthèse bibliographique. Biotechnologie, Agronomie, Société et Environnement, 15, 183-194.

[4] Waongo, A., Yamkoulga, M., Dabire-Binso, C.L., Ba, M.N. and Sanon, A. (2013) Post-Harvest Conservation of Cereals in the Southern Sudanian Zone of Burkina Faso: Peasant Perception and Stock Assessment. International Journal of Biological and Chemical and Sciences, 7, 1157-1167. https://doi.org/10.4314/ijbcs.v7i3.22

[5] Delobel, A. and Tran, M. (1993) Les Coléoptères des denrées alimentaires entreposées dans les régions chaudes. ORSTOM, Paris, $424 \mathrm{p}$.

[6] Stoll, G. (2000) Natural Crop Protection in the Tropics, Letting Information Come on Life. 2nd Edition, Margraf Verlag, Weikersheim, 376 p.

[7] Anonyme (2013) Maize Weevil Sitophilus zeamais (Motsch.) Canadian Grain Commission. 
[8] Danho, M. and Haubruge, E. (2003) Comportement de ponte et stratégie reproductive de Sitophilus zeamais [Coleoptera: Curculionidae]. Phytoprotection, 84, 59-67. https://doi.org/10.7202/007808ar

[9] FAO (1998) Le maïs dans la nutrition humaine.

[10] Sembène, M. (2000) Variabilité de l'espaceur Interne transcrit (ITS1) de l'ADN ribosomique et polymorphisme des locus microsatellites chez la bruche Caryedon serratus (Olivier): Différenciation en races d'hôtes et infestation de l'arachide au Sénégal. Thèse de Doctorat d'Etat en ES Sciences, Université Cheikh Anta Diop de Dakar, Dakar, 214 p.

[11] Santos, F. (2015) Analyse en composantes principales (ACP): Travaux pratiques avec le logiciel R. CNRS, UMR 5199 PCEA, 8 p. https://vibdoc.com

[12] Darrroch, J.N. and Mosimann, J.E. (1985) Canonical and Principal Components of Shape. Biometrika, 72, 241-252. https://doi.org/10.1093/biomet/72.2.241

[13] Dia, A.K.M., Sarr, A.G.R.J., Kafom, A., Ngom, D., Thiaw, C., Ndiaye, S. and Sembène, M. (2017) Identification morphométrique des populations de Tribolium castaneum Herbst (Coleoptera, Tenebrionidae) inféodées à trois céréales à Widou Thiengoli. Journal of Applied Biosciences, 119, 11929-11942.

https://doi.org/10.4314/jab.v119i1.9

[14] Sarr, A.G.R.J., Dia, C.A.K.M., Ndiaye, M.R., Ngom, D., Thiaw, C., Ndiaye, S. and Sembène, M. (2017) Morphometric Characterization of Sitophilus zeamais Motschulsky (Coleoptera: Curculionidae) Infesting Differents Maize Varieties in West and Central Africa. International Journal of Advanced Research (IJAR), 5, 1821-1835. https://doi.org/10.21474/IJAR01/5248

[15] Dia, A.K.M., Sarr, A.G.R.J., Kafom, A., Ngom, D., Thiaw, C., Ndiaye, S. and Sembène, M. (2018) Morphological Identification of Trophic Tribolium castaneum Populations Herbst (Coleptera, Tenebrionidae) in West Africa. International Journal of Advanced Research, 6, 203-216.

[16] Sembène, M. and Delobel, A. (1996) Identification morpho-métrique de populations soudano-sahéliennes de bruche de l'arachide, Caryedon serratus (Olivier) (Coleoptera Bruchidae). Journal of African Zoology, 110, 357-366.

[17] CILSS (2013) Flux commerciaux transfrontaliers de produits agricoles en Afrique de l'Ouest. 8 p.

[18] Garambois, N. (2016) Dynamiques des systèmes agraires et devenirs de l'agriculture familiale en Guinée. Notes Techniques, 133 p.

[19] CILSS (2017) Flux transfrontaliers de produits agricoles et d'élevage au Sahel et en Afrique de l'Ouest. 9 p.

[20] Camara, S. (1994) Production et utilisation du maïs en Guinée. Institut de recherche agronomique de Guinée, Kindia, république de Guinée. 9 p.

[21] Gueye, M.T., Seck, D., Watheley, J.P. and Lognay, G. (2012) Typologie des systèmes de stockage et de conservation du maïs dans l'est et le sud du Sénégal. Biotechnologie, Agronomie, Société et Environnement, 16, 49-58. 